\title{
VIOLÊNCIA OBSTÉTRICA: COMENTÁRIOS SOBRE O POSICIONAMENTO OFICIAL DO MINISTÉRIO DA SAÚDE A RESPEITO O TERMO
}

\author{
Iris Rabelo Nunes* \\ Roberto da Freiria Estevão*
}

\section{Resumo:}

Este artigo trata do posicionamento oficial adotado pelo Ministério da Saúde quanto ao termo "violência obstétrica", no qual a agência governamental concluiu que a expressão tem conotação inadequada e que pretende adotar estratégias para sua abolição. Visando analisar as possíveis consequências do posicionamento adotado, o presente estudo irá conceituar a violência obstétrica a fim de demonstrar como esta prática representa uma afronta aos direitos fundamentais das mulheres. Exemplos internacionais que visam prevenir e eliminar quaisquer formas de desrespeito e abuso durante o parto serão apresentados. Por fim, demonstrar-se-á de que formas o posicionamento do Ministério da Saúde é prejudicial.

Palavras-chave: direitos fundamentais; direitos das mulheres; direitos reprodutivos; violência obstétrica; administração pública.

\section{OBSTETRIC VIOLENCE: NOTES ABOUT THE OFFICIAL POSITIONING ADOPTED BY THE BRAZILIAN GOVERNMENT REGARDING THE TERM}

\begin{abstract}
:
This article addresses the official positioning adopted by the Brazilian Health Ministry about the term "obstetric violence", in which the governmental agency concluded that the expression transmits a harmful connotation and intends to adopt strategies to abolish its use. Searching to analyze possible consequences of the positioning, this study will conceptualize obstetric violence in order to demonstrate how this practice represents an offense to women's fundamental rights. Other international examples that seek to prevent and eliminate all the forms of disrespect and abuse during childbirth will be shown. Finally, it will be demonstrated how the Health Ministry's positioning is harmful.
\end{abstract}

Keywords: fundamental rights; reproductive rights; women's rights; obstetric violence; public administration.

\section{INTRODUÇÃO}

\footnotetext{
* Graduada em Relações Internacionais pela UNESP/Marília e em Direito pelo UNIVEM. Mestranda em Direito pelo UNIVEM. Linha de pesquisa: Construção do saber jurídico. Integrante do grupo de pesquisa DIFUNDE Direitos Fundamentais, democracia e exceção. E-mail: irisrabelonunes@ gmail.com.

${ }^{*}$ Graduado em Direito pela Faculdade de Direito da Alta Paulista Tupã-SP, especialista em Processo Penal pela PUC-SP, mestre em direito pelo UNIVEM, Doutor em Ciências Sociais pela UNESP/Marília, Líder.do grupo de pesquisa DIFUNDE - Direitos Fundamentais, democracia e exceção. E-mail: roberto_freiria@terra.com.br.
} 
O presente estudo busca analisar juridicamente as possíveis consequências do ofício no 017/19- JUR/SEC emitido ao Ministério da Saúde e do posicionamento desse órgão quanto ao termo "violência obstétrica, bem como pela repercussão do assunto nos meios médicos e jurídicos.

Inicialmente, o artigo expõe em linhas gerais o posicionamento adotado pelo governo brasileiro quanto ao tema e as notas de repúdio, de apoio e recomendações de outras instituições.

A seguir aborda-se a definição e o conceito de violência obstétrica com a finalidade de demonstrar de que forma esta prática representa uma afronta aos direitos reprodutivos, aos direitos das mulheres e aos direitos humanos/ fundamentais em geral.

Discute-se também o papel do Ministério da Saúde, como ente da Administração Pública, ao tratar da questão da violência obstétrica, bem como do Ministério Público Federal na defesa dos direitos coletivos. Isso, com fundamento nas recomendações de organizações internacionais que visam prevenir e eliminar quaisquer formas de desrespeito e abuso durante o parto.

Desta maneira, utilizando o método hipotético dedutivo, pretende-se demonstrar que o posicionamento adotado pelo Ministério da Saúde é prejudicial à garantia dos direitos humanos fundamentais.

\section{DO OFÍCIO EMITIDO PELO MINISTÉRIO DA SAÚDE E SUAS REPERCUSSÕES}

Em 03 de maio de 2019, o Ministério da Saúde emitiu um despacho em resposta a um Ofício ( $n^{\circ}$ 017/19-JUR/SEC) no curso do processo $n^{\circ}$ 125000.063808/2019-47, que solicitava um posicionamento oficial da entidade quanto ao termo "violência obstétrica", assinado pela Coordenadora-Geral de Saúde das Mulheres, pelo Diretor do Departamento de Ações Programáticas Estratégicas e pelo Secretário-Executivo Substituto.

O despacho inicia dizendo que não há consenso quanto ao conceito "violência obstétrica", porém sustenta que a definição de "violência" adotada pela Organização Mundial da Saúde ressalta a intencionalidade como fator fundamental para sua caracterização.

Diante da ausência da intenção de prejudicar ou causar dano por parte dos profissionais da saúde e de outras áreas no atendimento à mulher, conclui o Ministério que o 
uso deste termo "tem conotação inadequada, não agrega valor e prejudica a busca do cuidado humanizado no continuum gestação-parto-puerpério" (BRASIL, Ministério da Saúde, 2019).

Acrescenta o órgão do governo que a atuação ministerial é pautada em evidências científicas e guiada pelos princípios legais, éticos, conceituais e organizacionais do Sistema Único de Saúde (SUS) e que adota estratégias para diminuir a mortalidade materna e infantil e prevenir os danos decorrentes de intervenções necessárias para a preservação da vida da mãe e do bebê.

Cita programas e políticas de saúde implementadas para qualificar a atenção ao parto e ao nascimento e discussões ampliadas em aproximação com a academia, conselhos de especialidades e sociedades científicas.

O despacho conclui que, considerando que o termo "violência obstétrica" não agrega valor às discussões, o Ministério da Saúde adotará medidas para abolir o seu uso.

A publicação deste despacho/ofício teve bastante repercussão nos meios médicos e jurídicos, atraindo a manifestação de diversas entidades, tais como o requerimento da Comissão de Seguridade Social e Família (CSSF) da Câmara dos Deputados para a prestação de esclarecimentos, a Recomendação no 29/2019 do Ministério Público Federal (MPF), as notas de repúdio da Ordem dos Advogados do Brasil (OAB) e da Associação Nacional de Defensores Públicos Federais (ANADEF), bem como as notas de apoio o Conselho Federal de Medicina (CFM) e a Federação Brasileira das Associações de Ginecologia e Obstetrícia (FEBRASGO).

As repercussões no meio médico foram bastante favoráveis, sustentando que o uso da expressão "violência obstétrica" agride a comunidade médica, estigmatiza a prática médica e conturba a relação médico-paciente.

As repercussões no meio jurídico são notavelmente desfavoráveis ao posicionamento adotado pelo Ministério da Saúde, que em suas notas de repúdio destacam que a proibição do uso da expressão "violência obstétrica" dificulta sua identificação, ameniza a gravidade das condutas cometidas e censura atividades científicas que abordam o fenômeno.

A OAB concluiu sua nota de repúdio destacando que "o despacho, portanto, claramente fere os direitos fundamentais das mulheres, as políticas públicas de identificação, prevenção e erradicação da violência contra a mulher e o interesse público". 
A ANADEF destaca ainda que "julga a extinção do termo um verdadeiro preciosismo político, visto que a justificativa do Governo Federal foi associá-lo ao viés ideológico".

Dentre estas, destaca-se a Recomendação do MPF, que levou ao Ministério da Saúde diversas informações aparentemente ignoradas pelo órgão ministerial e recomendou que esclarecesse ao público por meio de uma nova nota que o uso da expressão "violência obstétrica", já consagrado em diversos meios continua sendo facultado independentemente da eventual preferência do Ministério da Saúde; que se abstivesse de empregar ações voltadas para a abolição do termo ao invés de ações voltadas para coibir as práticas; que adotasse as ações positivas sugeridas pela Organização Mundial da Saúde quanto ao tema.

As recomendações do Ministério Público Federal foram respeitadas pelo Ministério da Saúde, que publicou nova nota em 07 de junho de 2019.

\section{DA VIOLÊNCIA OBSTÉTRICA}

O Organização Mundial da Saúde (OMS) define violência como: “O uso intencional de força física ou poder, em ameaça ou na prática, contra si próprio, outra pessoa, ou contra um grupo ou comunidade, que resulte ou possa resultar em sofrimento, morte, dano psicológico, mal desenvolvimento ou privação" (1996, p.5).

O documento que elaborou a definição de violência também tratou da complexidade do termo "intencional", relacionando-o à intencionalidade de realizar o ato e não necessariamente à intencionalidade de causar dano.

Conforme exposto acima, no Ofício JUR/SEC 17/2019 o Ministério da Saúde descarta o uso do termo violência obstétrica diante da ausência da intenção de prejudicar ou causar dano por parte dos profissionais da saúde e de outras áreas no atendimento à mulher. Logo, de início, percebe-se o equívoco do Ministério da Saúde ao posicionar-se quanto a inaplicabilidade do termo "violência" diante da necessidade de intencionalidade do ato.

A violência contra a mulher é definida pela Convenção Interamericana para Prevenir, Punir e Erradicar a Violência contra a Mulher (Convenção de Belém do Pará) como: "qualquer ato ou conduta baseada no gênero, que cause morte, dano ou sofrimento físico, sexual ou psicológico à mulher, tanto na esfera pública como na esfera privada”. 
A violência obstétrica, por sua vez, foi conceituada na Lei Orgânica sobre o Direito das Mulheres a uma Vida Livre de Violência (VENEZUELA, 2007):

Se entende por violência obstétrica a apropriação do corpo e dos processos reprodutivos das mulheres por profissionais da saúde, que se expressa em tratamento desumanizado, abuso da medicalização e patologização dos processos naturais, trazendo consigo perda de autonomia e capacidade de decidir livremente sobre seus corpos e sexualidade, impactando negativamente a qualidade de vida das mulheres (tradução livre) ${ }^{1}$.

Em outras palavras, a violência obstétrica é qualquer intervenção danosa à integridade física ou psicológica praticada pelo profissional ou pela instituição de saúde contra a gestante, parturiente, puérpera ou neonato, seja durante o pré-natal, no parto, no pósparto, ou mesmo em situações de abortamento, sem o seu consentimento.

Silva e Serra (2017) descrevem a violência obstétrica como:

A violência obstétrica, conhecida também como violência institucional na atenção obstétrica corresponde a uma forma específica da violência de gênero, uma vez que há utilização arbitrária do saber por parte de profissionais da saúde no controle dos corpos e da sexualidade das parturientes. Consiste em uma expressão que agrupa as formas de violência e danos originados no cuidado obstétrico profissional, enquadrando-se nesse conceito, todos os atos praticados no corpo da mulher e do neonato sem o devido consentimento. (2017, p. 43)

Não se pode dissociar a violência obstétrica como forma de violência contra a mulher, uma vez está intimamente ligada a práticas discriminatórias de gênero, muitas vezes entrelaçadas a questões de classe e etnia, conforme aponta Aguiar:

Estes maus tratos vividos pelas pacientes, na maioria das vezes, segundo alguns autores, encontram-se relacionados a práticas discriminatórias por parte dos profissionais, quanto a gênero, entrelaçados com discriminação de classe social e etnia, subjacentes à permanência de uma ideologia que naturaliza a condição social de reprodutora da mulher como seu destino biológico, e marca uma inferioridade física e moral da mulher que permite que seu corpo e sua sexualidade sejam objetos de controle da sociedade através da prática médica. (2010, p. 15).

\footnotetext{
${ }^{1}$ Violencia obstétrica: Se entiende por violência obstétrica la apropiación del cuerpo y processos reproductivos de las mujeres por personal de salud, que se expresa en un trato deshumanizador, en um abuso de medicalización y patologización de los procesos naturales, trayendo consigo pérdida de autonomía y capacidad de decidir libremente sobre sus cuerpos y sexualidad, impactando negativamente en la calidad de vida de las mujeres.
} 
O surgimento do termo violência obstétrica está diretamente relacionado às modificações do processo de parir durante a história. No passado, o parto ocorria em ambiente domiciliar, realizado por parteiras e comadres, e acompanhado por mulheres de confiança da gestante. A assistência ao parto era culturalmente considerada um assunto de mulheres e os homens não se envolviam nesta atividade (SEIBERT et al, 2005).

A aproximação médica e, consequentemente, masculina ao parto ocorreu apenas no início do século XVI e se desenvolveu nos séculos XVIII e XIX, visto que apenas os homens tinham acesso à educação a nível superior. Nesta época foi criado o fórceps e foi adotado o parto horizontal como técnica para facilitar as intervenções, marcando oficialmente a transcrição entre o parto como evento privado, íntimo, feminino para um evento público, com presença de outros atores sociais (SEIBERT et al, 2005).

A crescente medicalização e institucionalização do parto que se seguiu, com o desenvolvimento das técnicas de cirurgia cesariana, anestesia, assepsia, seguindo o curso dos avanços tecnológicos e do desenvolvimento da medicina, acarretou por um lado a queda na mortalidade materna e infantil, porém por outro lado patenteou o momento do parto como um processo patológico, intervencionista e biologicista (SEIBERT et al, 2005).

A adoção deste modelo tecnocrático de parto coloca a parturiente em uma posição de passividade (paciente), sem autonomia sobre seu próprio corpo, em que deve apenas aguardar que o profissional escolha qual conduta seguir. (SEIBERT et al, 2005).

Neste sentido, Seibert et al (2005) descreve que:

Inúmeros procedimentos tecnocráticos são incorporados como rotina na assistência ao parto constituindo uma prática mecanizada, como o são os procedimentos de tricotomia da região genital, a enteróclise, a episiotomia e a anestesia. (p. 248)

O cerne da questão é que algumas práticas utilizadas institucionalmente na assistência ao parto são consideradas pela OMS como um fator de risco e a maneira arbitrária com que as intervenções rotineiras são aplicadas possuem mais fundamento nas crenças e preconceitos no tocante à sexualidade e saúde da mulher na sociedade patriarcal do que na seara cientifica.

Para Silva e Serra, "as rotinas técnicas, de tão repetidas, se 'descolam' de sua finalidade original, parecendo neutras aos seus agentes, não sendo observadas como recursos que podem limitar, promover ou violar os direitos das parturientes, a exemplo, as cesáreas eletivas e as episiotomias de rotina" (2017, p. 47). 
A pesquisa de opinião pública "Mulheres brasileiras e gênero nos espaços público e privado" (FUNDAÇÃO PERSEU ABRAMO,2010) nos permite ter uma noção mais exata da dimensão do problema no Brasil.

Quanto às violências sofridas durante o atendimento ao parto, 25\% das mulheres entrevistadas confirmaram ter sofrido violências, sendo que $10 \%$ relataram que o exame de toque foi feito de forma dolorosa, $10 \%$ não foram ofertadas ou receberam negativas de algum tipo de alívio para a dor, $9 \%$ foram tratadas com gritos pelos profissionais da saúde, $9 \%$ não receberam informações sobre os procedimentos realizados, $8 \%$ receberam negativas de atendimento e 7\% foram xingadas ou humilhadas (FUNDAÇÃO PERSEU ABRAMO,2010, p.173).

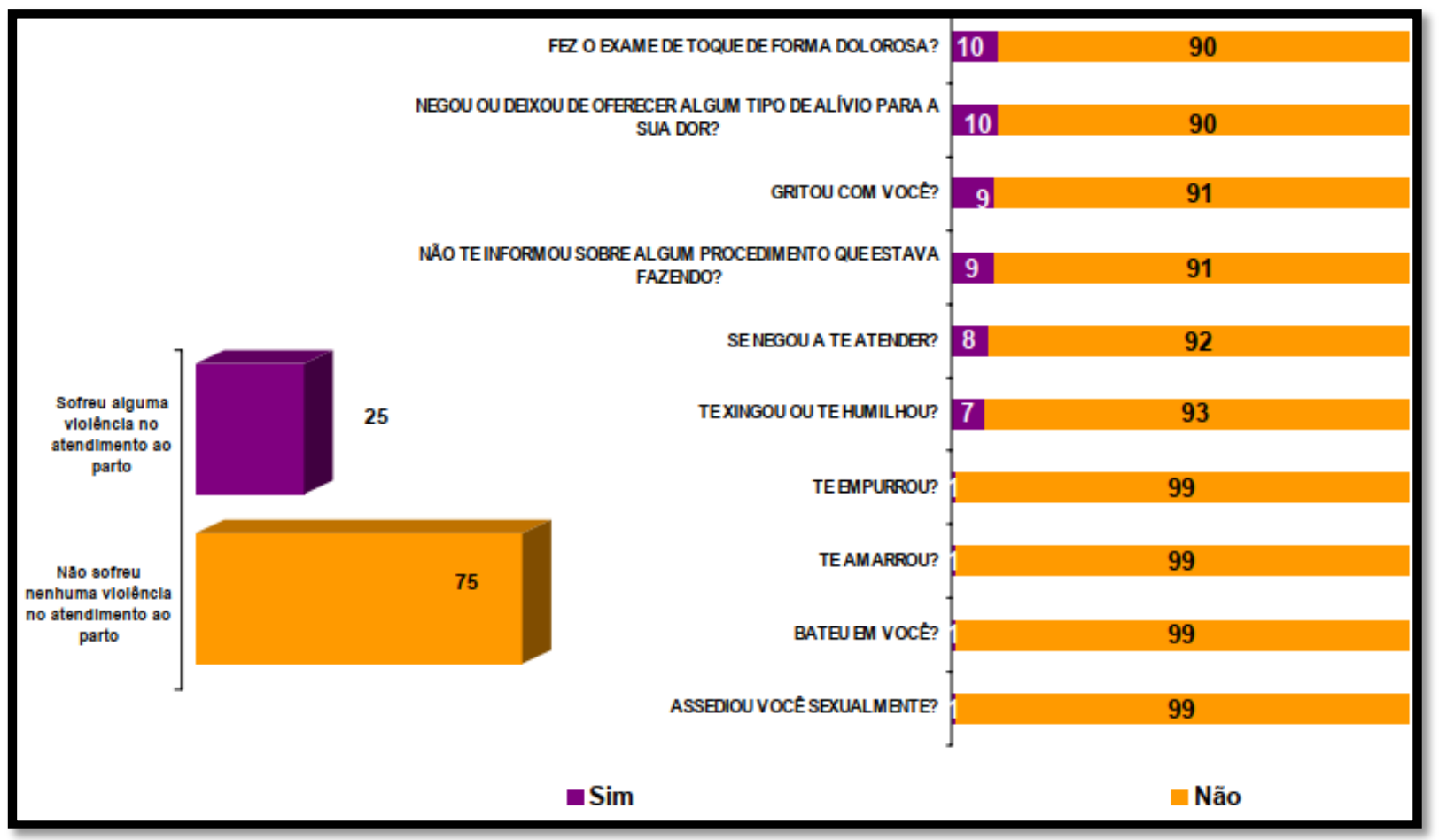

Figura 1: Violências sofridas durante o atendimento ao parto. (FUNDAÇÃO PERSEU ABRAMO,2010, p. 173)

Quando se tratam de ofensas verbais, 23\% das mulheres que tiveram partos naturais na rede pública ou privada já ouviram algum despropósito, tais como: "não chora não que ano que vem você está aqui de novo"; "na hora de fazer não chorou/ não chamou a mamãe, por que está chorando agora?"; "se gritar eu paro agora o que estou fazendo, não vou te atender"; "se ficar gritando vai fazer mal pro seu neném, seu neném vai ficar surdo" (FUNDAÇÃO PERSEU ABRAMO,2010, p. 177) 


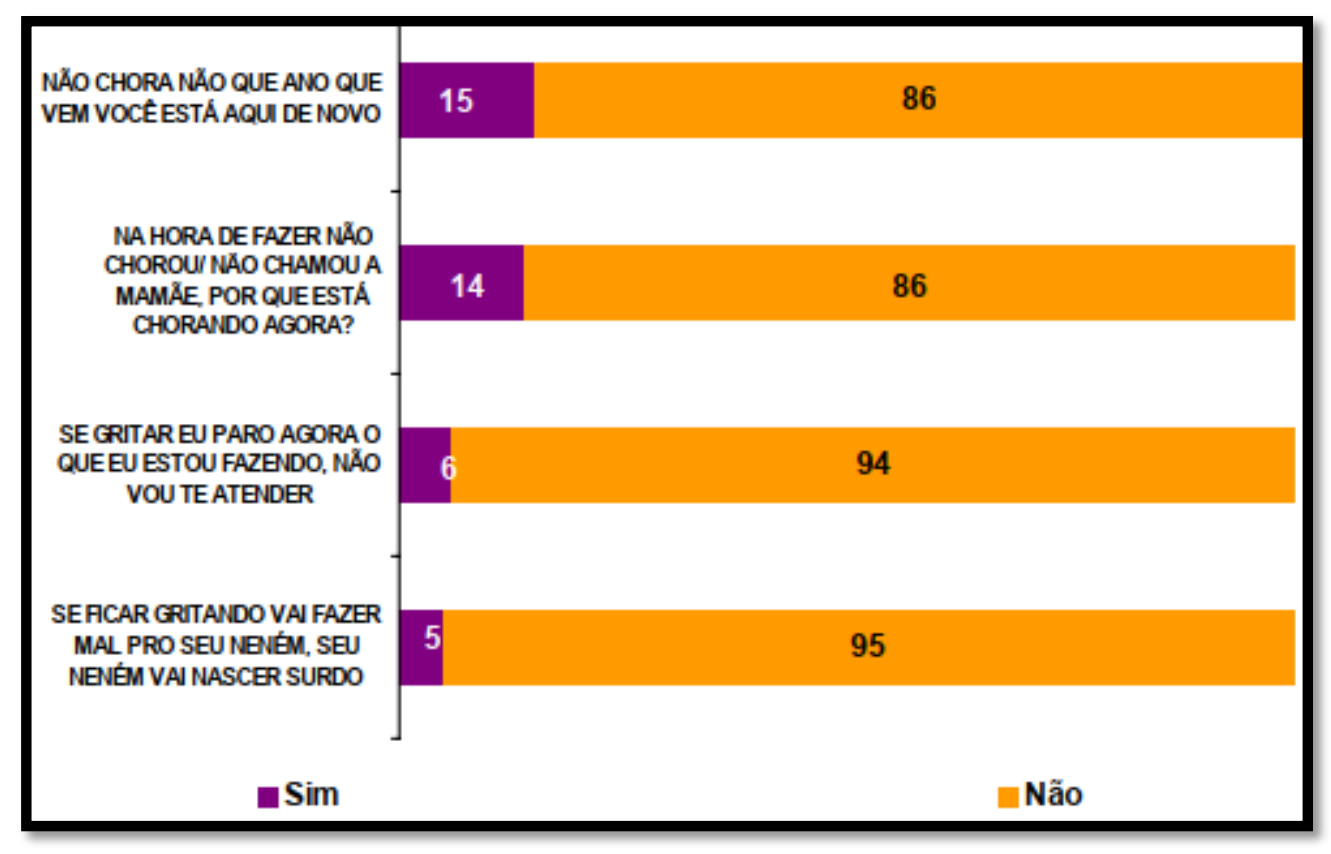

Figura 2: Frases ouvidas durante o parto. (FUNDAÇÃO PERSEU ABRAMO,2010, p. 177)

A Pesquisa "Nascer no Brasil" (LEAL, 2015) estima que quase um milhão de mulheres sejam submetidas à cesariana sem indicação obstétrica, representando $52 \%$ dos nascimentos no Brasil, o que indica maior exposição a riscos e gastos desnecessários. Quanto às mulheres que tiveram parto vaginal:

A maioria das mulheres foi submetida a intervenções excessivas, ficou restrita ao leito, sem estímulo para caminhar, sem se alimentar durante o trabalho de parto, usou medicamentos para acelerar as contrações (ocitocina), foi submetida a episiotomia (corte entre a vagina e o ânus) e deu à luz deitada de costas, muitas vezes com alguém apertando sua barriga (manobra de Kristeller). Esses procedimentos, quando utilizados sem indicação clínica, causam dor e sofrimento desnecessários e não são recomendados pela Organização Mundial da Saúde como procedimentos de rotina.

A Organização Mundial da Saúde (OMS, 2014) aponta que o problema da violência na assistência ao parto é um problema generalizado mundialmente e que cada vez mais pesquisas apontam um "quadro perturbador" nas experiências das mulheres durante a gravidez, em particular no parto.

Diante do quadro mundial dos relatos sobre desrespeitos e abusos durante o parto, a OMS (2014) publicou uma declaração intitulada "Prevenção e eliminação de abusos, desrespeito e maus-tratos durante o parto em instituições de saúde", em que sugere medidas 
que devem ser tomadas a nível mundial para evitar e eliminar estas práticas, entre elas o maior apoio dos governos.

Em 2018, a OMS emitiu nova recomendação sobre nascimentos e partos em que aborda com preocupação o aumento das taxas de cesáreas e outros procedimentos que somente deveriam ser utilizados em partos de risco, bem como a essencialidade da participação das mulheres no processo de tomada de decisões sobre os procedimentos realizados em seus corpos.

Considerando o exposto até aqui, passa-se a analisar no próximo tópico a participação da Administração Pública para evitar e eliminar o desrespeito e os abusos contra as mulheres durante a assistência ao parto, comparando as medidas adotadas pelo Brasil e outros países da América Latina.

\section{DO PAPEL DOS GOVERNOS NA ELIMINAÇÃO DA VIOLÊNCIA OBSTÉTRICA}

Conforme acima exposto, ao constatar a violência obstétrica como um problema de nível global, a Organização Mundial da Saúde (2014) elaborou medidas para prevenir e evitar abusos, desrespeitos e maus-tratos durante o parto em instituições de saúde, entendendo que:

Para obter um alto nível de respeito na assistência ao parto, os sistemas de saúde devem ser organizados e administrados de forma a garantir o respeito à saúde sexual e reprodutiva e os direitos humanos das mulheres. Enquanto muitos governos, grupos da sociedade civil e comunidades no mundo inteiro já destacaram a necessidade de abordar esse problema, em muitos casos, políticas para promover a assistência obstétrica respeitosa não foram adotadas, não são específicas ou não foram convertidas em ações significativas (p. 2)

Desta forma, a OMS sugeriu 5 medidas a serem tomadas no mundo inteiro para evitar e eliminar o desrespeito e os abusos contra as mulheres no momento do parto, sendo elas:

1. Maior apoio dos governos e de parceiros do desenvolvimento social para a pesquisa e ação contra o desrespeito e os maus-tratos;

2. Começar, apoiar e manter programas desenhados para melhorar a qualidade dos cuidados de saúde materna, com forte enfoque no cuidado respeitoso como componente essencial da qualidade da assistência;

3. Enfatizar os direitos das mulheres a uma assistência digna e respeitosa durante toda a gravidez e o parto; 
4. Produzir dados relativos a práticas respeitosas e desrespeitosas na assistência à saúde, com sistemas de responsabilização e apoio significativo aos profissionais;

5. Envolver todos os interessados, incluindo as mulheres, nos esforços para melhorar a qualidade da assistência e eliminar o desrespeito e as práticas abusivas.

No Brasil, o Ministério da Saúde é o ente da Administração Pública responsável pela organização de planos e elaboração de políticas públicas voltadas para a promoção, prevenção e assistência à saúde, de forma que cabe a esta instituição a elaboração de medidas que visem eliminar a violência obstétrica, sendo que o Sistema Único de Saúde (SUS) é a política pública desenvolvida em conjunto pela União, Unidades Federativas e Municípios para assegurar o direito à saúde.

O SUS, desenhado para responder setorialmente pela obrigação estatal de assegurar o direito à saúde, é a política pública que orienta a ação governamental desde 1990 (...). O Sistema foi implantado e vem funcionando, com uma gestão organizada segundo as diretrizes constitucionais de participação da sociedade e de descentralização. (ANDREWS; BARIANI, 2010, p. 212)

Contudo, como parte da Administração Pública, ao Ministério da Saúde cumpre apenas implementar as políticas de Estado e de governo nos moldes decididos pelos Poderes Legislativo e Executivos.

Quanto às definições de Estado e de Administração Pública, define Costin:

Em sua versão moderna, o Estado contém um conjunto de organismos de decisão (Parlamento e governo) e de execução (Administração Pública). Nessa concepção, a organização estatal possui uma dimensão legiferante - associada à produção de normas que regerão a vida social - e uma dimensão administrativa - associada ao cotidiano da gestão das instituições e das relações políticas. Assim, o Estado é mais amplo que o governo ou que a Administração Pública (COSTIN, 2010, p. 2)

No âmbito legislativo já é possível notar a preocupação da sociedade brasileira quanto à eliminação da violência obstétrica, pois já existem diversos diplomas legais a nível estadual $^{2}$ que preveem a adoção de medidas positivas para coibir as práticas desrespeitosas e os maus-tratos durante o parto.

\footnotetext{
${ }^{2}$ Lei ${ }^{\circ}$ 17.097/2017 do Estado de Santa Catarina; Lei no 5.217/2018 do Estado do Mato Grosso do Sul; Lei no 16.499/2018 do Estado de Pernambuco; Lei n 23.175/2018 do Estado de Minas Gerais.
} 
Desta maneira, caberia ao Ministério da Saúde como ente da Administração Pública responsável pela efetivação de políticas públicas na área da saúde e, portanto, propiciar a adoção das medidas sugeridas pela Organização Mundial da Saúde.

Quanto à atenção à assistência humanizada ao parto, o Ministério da Saúde desenvolveu em 2001 a cartilha "Parto, aborto e puerpério: assistência humanizada à mulher". Atualmente, $80 \%$ dos partos ocorridos no Brasil são pagos pelo SUS, seja em maternidades públicas ou mistas (LEAL, 2015, p. 3).

A cartilha desenvolvida pelo Ministério da Saúde (2001) tinha o objetivo de conscientizar os profissionais da saúde quanto à necessidade de humanização do momento do parto e da necessidade de avaliação crítica quanto ao uso de "práticas rotineiras" que podem gerar muitas intervenções desnecessárias e potencialmente iatrogênicas.

Contudo, a pesquisa "Nascer no Brasil" (LEAL, 2015), que entrevistou mulheres em maternidades públicas, privadas e mistas em 191 municípios nos anos 2011/2012, conforme exposto no tópico anterior, demonstra que as orientações da cartilha de cuidados humanizados do Ministério da Saúde não obtiveram sucesso na prática.

No entanto, apesar de incumbir ao Ministério da Saúde a promoção de medidas para evitar a violência obstétrica, o despacho/ofício JUR/SEC 17/2019 demonstrou que o órgão ministerial ignora completamente a realidade vivenciada pelas brasileiras no momento de parir, bem como os estudos nacionais e internacionais quanto ao tema e as orientações da Organização Mundial da Saúde.

Considerando a gravidade da forma como o ente da Administração Pública abordou o tema, após a publicação do pronunciamento emitido, o Ministério Público Federal, exercendo sua função institucional de "zelar pelo efetivo respeito dos Poderes Públicos da União e dos serviços de relevância pública quanto aos direitos assegurados na Constituição Federal relativos às ações e aos serviços de saúde e à educação", conforme dispõe o artigo $5^{\circ}$, inciso V, alínea “a” da Lei Complementar no 75/93, elaborou a Recomendação no 29/2019.

O Ministério Público Federal faz parte do Ministério Público da União e dentre suas funções destaca-se para os fins deste estudo "garantir o respeito pelos poderes públicos e pelos serviços de relevância aos direitos assegurados na Constituição" (COSTIN, 2010, p. 237).

Assim, com a expedição de recomendação pelo MPF, o Ministério da Saúde respondeu com o Ofício no 296/2019, desta vez assinado por Erno Harzeim, Secretário de 
Atenção Primária à Saúde, informando todas as políticas de atenção ao parto e nascimento pelo órgão fomentadas (Rede Cegonha - 2011; Diretriz de Atenção à Gestante: Operação Cesariana - 2016; Diretriz Nacional de Assistência ao Parto Normal -2017), informando que elas estão em consonância com as determinações da OMS e baseadas nas melhores evidências científicas disponíveis.

Por fim, o Ministério da Saúde reconheceu como direito das mulheres a utilização do termo que melhor represente as experiências vivenciadas e "compreende que sua atuação está centrada em superar as situações de maus tratos, desrespeito, abusos e uso de práticas não baseadas em evidências científicas, através de ações positivas e em parceria com secretarias de saúde e instituições envolvidas com a temática" (BRASIL, 2019)

Considerando o exposto, percebe-se que a atuação do Ministério Público Federal no zelo institucional das funções do Ministério da Saúde foi bastante salutar no caso em concreto, pois permitiu ao ente da Administração Pública que reparasse o equívoco cometido antes que pudesse repercutir negativamente na qualidade do serviço público oferecido.

\section{CONSIDERAÇÕES FINAIS}

Diante de todo o exposto no decorrer do presente artigo, percebe-se que o Ofício $\mathrm{n}^{\circ}$ 017/2019 - JUR/SEC emitido pelo Ministério da Saúde cometeu um grave equívoco ao ignorar a gravidade do problema enfrentada pelas mulheres brasileiras em relação à violência institucional obstétrica, restringindo-se a analisar a "conotação negativa" da expressão.

O posicionamento ministerial de maio/2019 foi na contramão de todas as recomendações da Organização Mundial da Saúde e das melhores evidências científicas, restringindo-se a analisar apenas a conveniência do uso da expressão.

O Ministério da Saúde baseou-se em definição equivocada de "violência" ao descartar a utilização do termo diante da ausência de intencionalidade do profissional da saúde de provocar danos à parturiente e desconsiderou a gravidade das denúncias de desrespeitos, maus tratos e procedimentos realizados sem consentimento da mulher e sem amparo científico.

As práticas violentas citadas no decorrer do estudo constituem verdadeiras afrontas aos direitos reprodutivos e aos diretos humanos fundamentais das mulheres, com claro contorno de discriminação de gênero. 
Desta forma, a atuação do Ministério Público Federal no zelo do efetivo respeito dos serviços de saúde foi primordial para prevenir a possibilidade de repercussões negativas que poderiam enfraquecer as ações positivas já adotadas e amparar teses defensivas de profissionais da saúde que atuem de forma desrespeitosa.

Com o segundo ofício emitido pelo Ministério da Saúde foi possível verificar que surtiu efeito a recomendação do MPF, ao oportunizar o saneamento dos equívocos cometido pelo órgão ministerial ao analisar o tema da violência obstétrica apenas em face da suposta "conotação negativa" do termo e pronunciar-se acerca das ações positivas já adotadas para promover a humanização do parto.

Conclui-se que a violência obstétrica deve ser tratada como questão de maior gravidade e que é papel do Estado, por meio da Administração Pública, garantir a adoção das boas práticas obstétricas recomendadas pela Organização Mundial da Saúde e coibir os desrespeitos, maus tratos e a realização de práticas negativas na assistência ao parto.

Considerando que a adoção de estratégias para abolir o uso da expressão "violência obstétrica" representaria um desserviço às necessárias práticas adotadas para a prevenção e eliminação dos abusos, desrespeitos e maus tratos durante o parto em instituições de saúde, andou muito bem o órgão ministerial ao rever seu posicionamento.

\section{REFERÊNCIAS BIBLIOGRÁFICAS}

ANDREWS, Christina W.; BARIANI, Edson (org.). Administração Pública no Brasil: breve história política. São Paulo: Editora Unifesp, 2010.

BRASIL. Ministério da Saúde. Despacho/Ofício no 017/19 - JUR/SEC, de 03 de maio de 2019. Disponível em: https://bit.ly/2LcGgXI Acesso em 28 jul. 2019.

BRASIL. Ministério da Saúde. OFÍCIO No 296/ 2019/ COSMU/ CGCIVI/ DAPES/ SAPS/ MS, de 07 de junho de 2019. Disponível em: https://bit.ly/30QHoXx Acesso em 28 jul. 2019.

BRASIL. Ministério da Saúde. Parto, aborto e puerpério: assistência humanizada à mulher. Brasília: Ministério da saúde, 2001. Disponível em: https://bit.ly/2zAm0Ka Acesso em 28 jul. 2019.

BRASIL. Ministério Público Federal. Recomendação no 29/2019. Disponível em: https://bit.ly/2LnRueo Acesso em 28 jul. 2019. 
BRASIL. Câmara dos Deputados. Projetos de Lei e Outras Proposições. REQ 129/2019 CSSF. Disponível em: Disponível em: https://bit.ly/2Sh32ki Acesso em 28 jul. 2019.

BRASIL. Lei Complementar no 75/1993. Disponível em: https://bit.ly/2PymY4h Acesso em 28 jul. 2019.

CONSELHO FEDERAL DE MEDICINA. Processo Consulta CFM n 22/2018 - Parecer CFM no 32/2018. Disponível em: https://bit.ly/2LdwoOB Acesso em 28 jul. 2019.

COSTIN, Claudia. Administração pública. Rio de Janeiro: Elsevier, 2010.

CONVENÇÃO INTERAMERICANA DE DIREITOS HUMANOS. Convenção interamericana para prevenir, punir e erradicar a violência contra a mulher, "Convenção de Belém do Pará”, adotada em Belém do Pará, Brasil, 9 de jun.1994. Disponível em: https://bit.ly/2FO6MqK Acesso em 28 jul. 2019.

FREITAS, Juarez. Controle dos Atos Administrativos e os princípios fundamentais. $5^{\mathrm{a}}$ ed. São Paulo: Editora Malheiros, 2013.

FUNDAÇÃO PERSEU ABRAMO. Mulheres brasileiras e gênero nos espaços público e privado. São Paulo: Sesc/Fundação Perseu Abramo, 2010. Disponível em: https://bit.ly/2ZssxFT Acesso em 28 jul. 2019.

GUIMARÃES, Liana Barcelar Evangelista; JONAS, Eline; AMARAL, Leila Rute Oliveira Gurgel do. Violência Obstétrica em maternidades públicas do estado do Tocantins. Revista Estudos Feministas. Florianópolis, 26[1], 2018. Disponível em:

http://dx.doi.org/10.1590/1806-9584.2018v26n143278 Acesso em 28 jul. 2019.

LEAL, Maria do Carmo (coord.). Nascer no Brasil: Sumário Executivo Temático da Pesquisa. Rio de Janeiro: Fiocruz, 2015. Disponível em https://bit.ly/2ZnClRA Acesso em 28 jul. 2019.

Nota à imprensa e à população. Conselho Federal de Medicina, 2019. Disponível em: https://bit.ly/2LWXnOY Acesso em 28 jul. 2019

Nota de apoio da FEBRASGO ao despacho do Ministério da Saúde sobre a utilização da expressão "violência obstétrica. Federação Brasileira das Associações de Ginecologia e Obstetrícia, 2019. Disponível em: https://bit.ly/2JN50ow Acesso em 28 jul. 2019.

Nota de repúdio. Associação Nacional dos Defensores Públicos Federais, 2019. Disponível em: https://bit.ly/2NV1GiV Acesso em 28 jul. 2019.

OAB repudia despacho do Ministério da Saúde que elimina o termo violência obstétrica. Conselho Federal da OAB, 2019. Disponível em: https://bit.ly/2H9KazN Acesso em 28 jul. 2019. 
ORGANIZAÇÃO MUNDIAL DA SAÚDE. Prevenção e eliminação de abusos, desrespeito e maus-tratos durante o parto em instituições de saúde. Genebra: WHO, 2014. Disponível em: https://bit.ly/30YT6za Acesso em 28 jul. 2019.

ORGANIZAÇÃO MUNDIAL DA SAÚDE. Global consultation on violence and health. Violence: a public health priority. Genebra: WHO, 1996. Disponível em: https://bit.ly/2PfGIcJ Acesso em 28 jul. 2019.

ORGANIZAÇÃO MUNDIAL DA SAÚDE. WHO recommendations. Intrapartum care for a positive childbirth experience. Genebra: WHO, 2018. Disponível em: https://bit.ly/2ByJZvB Acesso em 28 jul. 2019.

SILVA, Delmo Mattos da; SERRA, Maiane Cibele de Mesquita. Violência obstétrica: uma análise sob o prisma da autonomia, beneficência e dignidade da pessoa humana. Revista Brasileira de Direitos e Garantias Fundamentais, v. 3, n. 2, p.42-65, Jul/Dez 2017. Disponível em: https://bit.ly/346WHxb Acesso em 28 jul. 2019.

SEIBERT, Sabrina Lins et al. Medicalização x Humanização: o cuidado ao parto na história. Revista Enfermagem UERJ, 2005 p.245-251. Disponível em: https://bit.ly/30GBgkx Acesso em 28 jul. 2019.

VENEZUELA. Ley orgânica sobre el derecho de las mujeres a uma vida libre de violência. Disponível em: https://bit.ly/2zH94lz Acesso em 28 jul. 2019. 